\title{
Una parada en el camino: Estrategia de prevención secundaria de la trata en Andalucía*
}

A stop along the way: Secondary prevention strategy of trafficking in Andalucia

\author{
ELISA GARCÍA ESPAÑ̃
}

Universidad de Málaga (España)

https://orcid.org/0000-0002-3224-6932

JACQUELINE CARVALHO DA SILVA

Universidad de Málaga (España)

https://orcid.org/0000-0002-8875-6050

ELENA CASADO PATRICIO

Universidad de Málaga (España)

elenacasado@uma.es

https://orcid.org/0000-0002-3299-0913

BERTHA PRADO MANRIQUE

Universidad de Málaga (España)

https://orcid.org/0000-0001-6970-7280

${ }^{*}$ Este trabajo es fruto de los resultados del Proyecto "Víctimas desprotegidas e invisibles: Valoración de nuevas fórmulas de protección de mujeres y menores inmigrantes víctimas", financiado por el Programa Operativo FEDER Andalucía 2014-2020 (UMA18-FEDERJA-038), siendo la IP Elisa García España. 
Resumen: La frontera sur de España es una de las principales puertas de entrada a Europa para la inmigración irregular por mar. Entre las personas que llegan por vía marítima, las mujeres subsaharianas embarazadas y / o acompañadas de niños, niñas o adolescentes plantean un desafío especial a las autoridades encargadas de la lucha contra la trata de personas con fines de explotación sexual, así como para la protección de los menores en movimiento. La Fiscalía General del Estado o la Defensoría del Pueblo en España han denunciado el riesgo que corren estas mujeres de ser explotadas en su tránsito por Europa. El programa ÖDOS es un programa pionero y especializado de primera acogida y acompañamiento de estas familias migrantes para dar respuesta a una necesidad imperiosa e invisible de protección y prevención de la victimización con enfoque de género e infancia. Este artículo presenta los resultados de la evaluación externa de los dos primeros años del programa ÖDOS (2018 y 2019). Se enfoca en la valoración de su eficacia. Los resultados muestran que el programa ÖDOS es una iniciativa necesaria para la prevención secundaria de la trata y para la protección de la infancia en movimiento, aunque la continuidad del trayecto migratorio hacia Francia de la mayoría de las mujeres atendidas apunta a un gran desafío: la necesidad de estrategias internacionales de seguimiento para una efectiva protección de estas mujeres y menores.

Abstract: Spanish southern border is one of the main gateways to Europe for irregular immigration by sea. Among those who arrive, sub-Saharan women who are pregnant and / or accompanied by children or adolescents pose a special challenge to the authorities in charge of the fight against trafficking in persons for the purpose of sexual exploitation, as well as for the protection of minors on the move. The Office of the Attorney General of the State or the Ombudsman's Office in Spain have denounced the risk that these women run of being exploited in their transit through Europe. The ÖDOS program is a pioneer and specialized program for the first reception and accompaniment of these migrant families to respond to an urgent and invisible need for protection and prevention of victimization with a gender and childhood approach. This article presents the results of the external evaluation of the first two years of the ÖDOS program (2018 and 2019). It focuses on evaluating its effectiveness. The results show that the ÖDOS program is a necessary initiative for the secondary prevention of trafficking and for the protection of children on the move, although the continuity of the migratory path towards France of most of the women attended points to a great challenge: the need for international follow-up strategies for effective protection of these women and minors.

Palabras claves: mujeres migrantes, infancia, protección, prevención, víctimas, trata.

Keywords: migrant women, childhood, protection, prevention, victim trafficking.

Sumario: 1. INTRODUCCIÓN. 2. ENFOQUE Y OBJETIVO DE LA EVALUACIÓN. 3. METODOLOGÍA. 4. RESULTADOS SOBRE LA EFICACIA DEL PROGRAMA. 4.1. Alcance del programa y perfil de la población diana. 4.2. Eficacia según los objetivos del programa. 5. CONCLUSIONES. 6. BIBLIOGRAFÍA. 


\section{INTRODUCCIÓN}

Las mujeres subsaharianas acompañadas de niños, niñas y/o adolescentes (NNA), y/o embarazadas que llegan a España en patera suponen un desafío para las políticas públicas encargadas de la lucha contra la trata de personas con fines de explotación sexual o laboral, así como para las de protección de menores. Instituciones públicas como la Fiscalía General del Estado o el Defensor del Pueblo alertan sobre el riesgo que corren estas personas de ser explotadas en su tránsito por Europa ${ }^{1}$. Tras la llegada a las costas andaluzas, al no ser percibido por las autoridades concernidas el riesgo de explotación sexual o laboral posterior, aquellas y los NNA son derivados a recursos de asistencia humanitaria, de donde en muchos casos huyen, posiblemente engañadas o amenazadas por sus tratantes ${ }^{2}$.

El programa ÖDOS se planteó precisamente como un recurso especializado para dar respuesta a esta apremiante e invisible necesidad en Andalucía. ÖDOS es un programa pionero de atención integral a esas mujeres y NNA a su cargo que se encuentran en una situación de riesgo victimológico. Este riesgo puede producirse, bien porque posiblemente hayan realizado el trayecto a través de redes de trata de seres humanos, sabiéndolo o no, o bien porque corran un grave riesgo de que su única salida de supervivencia en Europa sea a través de contextos irregulares que conducen, con cierta frecuencia, a entornos de prostitución forzada y de explotación laboral.

ÖDOS se diseñó con una serie de recursos técnicos y humanos que se orientan al restablecimiento, recuperación y protección de estas mujeres y de los NNA a su cargo por medio de una atención experta durante la primera acogida tras su llegada a costas y ofreciendo posteriormente una alternativa de vida segura, así como posibilidades de inclusión social en España. Estos objetivos se abordan desde un triple enfoque: de género, de infancia y de derechos humanos. Para ello, el programa cuenta con un tejido de apoyo $\left(\right.$ Red ÖDOS ${ }^{3}$ ) compuesto por diversas entidades españolas y extranjeras (de Marruecos y Francia), entre las que se encuentran universidades, congregaciones religiosas, asociaciones sin ánimo de lucro e instituciones jurídicas, además de agentes clave como la policía nacional, el ayuntamiento de Montilla o la fiscalía de Córdoba.

El organigrama del programa ÖDOS se centraliza en un grupo motor compuesto inicialmente por cuatro especialistas en género, infancia y derechos humanos y con experiencia en intervención. El grupo motor diseñó el programa en 2017, puso en marcha

\footnotetext{
${ }^{1}$ DEFENSOR DEL PUEBLO (2012). Informe anual DEFENSOR DEL PUEBLO Informe Anual a las Cortes Generales 2012; FISCALÍA GENERAL DEL ESTADO (2019) Memoria año fiscal 2019. Ministerio Fiscal.

${ }^{2}$ FISCALÍA GENERAL DEL ESTADO (2014) Memoria año fiscal 2014. Ministerio Fiscal.

${ }^{3}$ La red ÖDOS se compone de las siguientes instituciones públicas y privadas: Servicio Jesuita a Migrantes, Asociación Claver, Esclavas (España y Francia), Hospitalarias, Delegación diocesana de migraciones de Nador (Marruecos), Fundación Yedra, Caritas, Asociación Caribú, Fundación Ellacuría de Bilbao, Ayuntamiento de Montilla, Fundación Etea-Loyola, Fundación Abogacía española, la Merced Migraciones, Universidad de Loyola, Fundación Abogado Uría y Fiscalía de Córdoba.
} 
el recurso residencial de primera acogida (fase I) y consiguió adherir al programa a todas las entidades que conforman la Red ÖDOS y a los agentes clave (Policía Nacional, ACNUR, ACCEM, OIM y Ayuntamiento de San Sebastián).

El programa ÖDOS se estructura en dos fases: la primera (fase I) es un recurso residencial, conocido como La Muela, para las mujeres y NNA a su cargo por un tiempo de entre 3 y 6 meses, gestionado por la Fundación Emet-Arcoíris en Montilla, Córdoba. En este recurso hay una dirección, una trabajadora social, una psicóloga y ocho educadoras, además de monitores. Aunque esta fase se puso en marcha gracias a la financiación privada, desde el inicio buscaba constituirse en una política pública. De hecho, dos años después de su implementación esta primera fase ya cuenta con algunas plazas financiadas con fondos públicos de ayuda humanitaria.

La segunda fase está integrada por entidades que componen la Red ÖDOS. Estas se comprometen a seguir acompañando y ofreciendo alternativas de inclusión a las mujeres y NNA en España tras su salida del recurso residencial en fase I, con una duración indefinida y adaptada a los procesos inclusivos de cada caso.

En el esbozo inicial del programa ÖDOS se incluyó la realización de una evaluación externa con el propósito de mejorar la ejecución del programa, ya que de esta depende que los resultados alcanzados sean eficaces y eficientes. En este artículo se presentan los resultados más destacables de la evaluación externa de los dos primeros años de ejecución del programa ÖDOS enfocados en la valoración de su eficacia.

\section{ENFOQUE Y OBJETIVO DE LA EVALUACIÓN}

Una evaluación de programas consiste en conocer el funcionamiento de una determinada intervención, mediante la aplicación de métodos de investigación social, con el objetivo de alcanzar un juicio valorativo sobre su utilidad lo más exacto y sistemático posible ${ }^{4}$. Entre las diferentes funciones que puede desempeñar una evaluación de programas ${ }^{5}$ esta adoptó la de perfeccionamiento o mejora (improvement). En este caso la evaluación se constituye como una herramienta metodológica que permite la retroalimentación y el aprendizaje desde la propia práctica. En este sentido, la evaluación resulta imprescindible como garante de la calidad.

Con la evaluación de un programa se obtienen datos e información empírica a partir de las cuales es posible tomar decisiones sobre la mejora de la orientación del programa (pertinencia), su puesta en marcha (implementación) y los resultados conseguidos (eficacia). Con la evaluación se trata de demostrar si el programa es útil y necesario para

\footnotetext{
${ }^{4}$ CHELIMSKY, E. [ed.] (1985) Program Evaluation: Patterns and Directions. Washington, DC: ASPA PAR Classics VI; WEISS, C. H. (1998). Evaluation. Methods for Studying Programs and Policies. Second Edition. Prentice Hall; ROSSI, P.H. \& FREEMAN H.E. (1989). Evaluación. Un enfoque sistemático para programas sociales. Traducción de la 2 ed. en inglés. Trillas.

5 STUFFEBEAM, D. \& SHINKFIELD, A. (1987). Evaluación sistemática: guía, teoría y práctica. Barcelona. Paidos. taking [Versión electrónica]. Journal of Educational Psychology, 95(2), 335-346.
} 
la realidad en la que se interviene y si se ha ejecutado de manera satisfactoria. Además, se valora si se han conseguido los resultados esperados con eficiencia, y si se cumplen estándares de transparencia, lo que permite tomar decisiones sobre su continuidad o redefinir las estrategias a seguir 6 .

El objetivo de esta evaluación fue valorar las siguientes dimensiones del programa ÖDOS: pertinencia, implementación, eficacia, eficiencia, satisfacción y transparencia. El análisis de todas ellas permitió conocer detalladamente las bondades y mejoras del programa. Cada dimensión permite profundizar en apartados concretos, así como enfocar la valoración desde diferentes perspectivas. Todas ellas fueron evaluadas y presentadas en un informe de evaluación al grupo motor, agentes clave y miembros del programa ${ }^{7}$. Nos enfocaremos aquí en la dimensión eficacia para presentar y debatir los resultados conseguidos por el programa durante sus dos primeros años de puesta en marcha.

El criterio de eficacia mide el grado en que se han alcanzado los objetivos establecidos en el programa ${ }^{8}$. A partir de la evaluación de esta dimensión se podrán valorar los resultados inmediatos (a corto plazo) de la intervención. Para evaluar el impacto (a largo plazo) sería necesario incluir el factor tiempo y evaluar algunos años más tarde qué influencia tiene en la vida de las mujeres y NNA la experiencia de pasar por el programa. En esta ocasión, el objetivo de esta propuesta de evaluación se centra solo en los resultados y no en el impacto, ya que el programa se evaluó tras dos años de su puesta en marcha, lo que constituye una limitación temporal para analizar dicho aspecto.

\section{METODOLOGÍA}

Para evaluar la eficacia del programa se utilizó la metodología propia de la investigación social. Además, se optó por un enfoque participativo y formativo ya que se pretendía en todo momento el perfeccionamiento y mejora del programa. Por ello, el personal de intervención, formado por trabajadoras sociales, educadoras sociales y psicólogas, y dirección de La Muela, así como el grupo motor, participaron en la construcción de algunos de los indicadores de evaluación. Estos y representantes de la fase II también participaron en la interpretación de los resultados preliminares. Esa retroalimentación bidireccional entre el equipo evaluador, al presentar los datos, y los diferentes componentes del programa ÖDOS, al exponer sus impresiones e interpretaciones, resultó instructivo para ahondar en algunos aspectos mejorables del programa.

\footnotetext{
6 JUNTA DE ANDALUCÍA (2016). La Evaluación de Políticas Públicas. Instituto Andaluz de administración pública - Conserjería de hacienda y administración pública. Recuperado de: http://www.juntadeandalucia.es/institutodeadministracionpublica/institutodeadministracionpublica/public o/anexos/evaluacion/EvaluacionPoliticasPublicas.pdf

${ }^{7}$ GARCÍA-ESPAÑA, E., CARVALHO DA SILVA, J. CASADO PATRICIO, E, y PRADO MANRIQUE, B. (2020). Resumen ejecutivo: Evaluación Programa ÖDOS.

${ }^{8}$ AGENCIA DE EVALUACIÓN Y CALIDAD - AEVAL (2015). Guía práctica para el diseño y la realización de evaluaciones de políticas públicas. Enfoque AEVAL. Agencia de evaluación y calidad. Ministerio de Hacienda y Administraciones Públicas
} 
A continuación, se detallan los parámetros y técnicas utilizados:

El periodo de tiempo en el que se enmarcó la evaluación abarca los dos primeros años del programa, esto es, desde sus inicios en marzo de 2018 hasta el 30 de septiembre de 2020. Este marco temporal comprende la fase piloto del programa y permite observar la tendencia de la intervención y sus resultados.

El universo poblacional de la evaluación son todas las mujeres y NNA que han pasado por el recurso residencial La Muela (fase I). No obstante, la evaluación ha utilizado como muestra las mujeres y NNA atendidas desde el inicio del programa hasta el 30 de marzo de 2020. Se decidió hacer un corte seis meses antes de finalizar la evaluación (30 de septiembre de 2020) porque ello permitía incorporar aspectos relacionados con la derivación y el seguimiento de las familias que aún permanecían en La Muela a la fecha de corte, y completar así el ciclo de intervención.

Las técnicas de recogida de datos han sido tanto cuantitativas como cualitativas. La recogida de datos cuantitativos fue realizada por el personal del recurso residencial La Muela y el grupo motor del programa durante la atención directa con las mujeres y NNA. En una reunión de trabajo entre el equipo de intervención, el grupo motor y el equipo evaluador se elaboró una ficha de indicadores de evaluación que debía ser cumplimentada por las propias educadoras del programa para cada mujer y NNA en dos momentos diferentes: Uno, en el momento de la llegada de la mujer y NNA al recurso residencial La Muela (pre) y, otro, en el momento de la salida de la mujer de ese recurso (post). Algunas de estas cuestiones pre- y post- se basan en datos objetivos (enfermedades a la llegada y salida de la mujer, por ejemplo), pero otras se sustentan en percepciones del equipo de intervención de La Muela. A estas últimas también las dotamos de fiabilidad por varios motivos: En primer lugar, porque el foco de la respuesta estaba puesto en la mujer o en el/la NNA, aun cuando los resultados reflejan en buena medida el trabajo realizado por el equipo de intervención; y porque, como se podrá comprobar a lo largo del artículo, existen datos que no son satisfactorios, lo que prueba que las respuestas se trataron de dar con objetividad. Además, el equipo de evaluación y el grupo motor elaboraron una ficha de indicadores para identificar factores de incidencia jurídica. En este caso, los indicadores hacen referencia a las gestiones realizadas y a los resultados jurídicos alcanzados con las mujeres y NNA con los que se han intervenido.

La recogida de datos cualitativos se ha realizado, por una parte, a través del equipo de intervención al registrar de forma narrativa los acontecimientos de la intervención en la agenda diaria, en el plan de intervención integral (PII) y en documentos varios. El equipo de evaluación llevó a cabo un análisis documental de los registros de información de la fase I y realizó entrevistas estructuradas con el grupo motor, el personal del recurso residencial de fase I, la red y los agentes clave con la finalidad de indagar el grado de satisfacción con el programa, los nudos que estaban limitando la intervención en las fases I y II, y las posibles mejoras.

Las herramientas utilizadas en la fase I del programa ÖDOS para recoger información han sido múltiples y con diversa utilidad, como se detalla en la tabla 1. 
Tabla 1. Resumen de las herramientas de recogida de datos y su utilidad

\begin{tabular}{|c|c|}
\hline Herramienta & Utilidad \\
\hline $\begin{array}{l}\text { Agenda diaria (registro de la dinámica diaria de } \\
\text { trabajo) }\end{array}$ & - Comunicación interna. \\
\hline $\begin{array}{l}\text { PII (registro individual mujeres y menores: datos } \\
\text { personales y datos de la intervención individual) }\end{array}$ & $\begin{array}{l}\text { - Consulta para intervención y } \\
\text { acompañamiento } \\
\text { (comunicación interna). } \\
\text { - Fuente de datos para } \\
\text { seguimiento, evaluación e } \\
\text { investigación }\end{array}$ \\
\hline $\begin{array}{l}\text { Informe psicosocial (información consolidada al } \\
\text { cierre de la intervención) }\end{array}$ & $\begin{array}{l}\text { - Traslado de información para } \\
\text { la derivación a la fase II. }\end{array}$ \\
\hline $\begin{array}{l}\text { Ficha de indicadores de evaluación (registro } \\
\text { individual de mujeres y menores respecto a la } \\
\text { evolución de su estado a la llegada y a la salida de la } \\
\text { fase I) }\end{array}$ & $\begin{array}{l}\text { - Fuente de datos para } \\
\text { seguimiento, evaluación e } \\
\text { investigación. }\end{array}$ \\
\hline $\begin{array}{l}\text { Documentos varios (cuadrante de entradas y salidas, } \\
\text { cuadrante de seguimiento, informes jurídicos...) }\end{array}$ & $\begin{array}{l}\text { - Fuente de datos seguimiento, } \\
\text { evaluación e investigación. }\end{array}$ \\
\hline
\end{tabular}

Fuente: Base de datos ÖDOS en Google Drive y en la aplicación informática ÖDOS.

Algunos de esos instrumentos de recogida de información del programa fueron incorporados como fuente de datos para la evaluación. En la tabla 2 se expone el uso realizado de tales herramientas clasificadas según su utilidad en términos cuantitativos y cualitativos.

Los datos cuantitativos fueron introducidos de manera manual por el equipo de evaluación en una base de datos ad hoc creada en el software estadístico SPSS (Statistical Package fot the Social Sciences), donde se han explotado a partir de diversas pruebas estadísticas como, por ejemplo, análisis descriptivos para conocer la media y los porcentajes de cada uno de los indicadores analizados, así como pruebas bivariantes o multivariantes, para comprobar con todo ello la calidad de la intervención. Concretamente, se realizó la prueba no paramétrica de Wilconxon, que es un test para comparar el rango medio de las dos muestras relacionadas y determinar si existen diferencias entre ellas. También se han utilizado tablas de contingencia para analizar la relación entre dos o más variables. 
Tabla 2. Fuente de datos utilizados en la evaluación del programa ÖDOS

\begin{tabular}{|c|c|c|c|c|c|}
\hline \multicolumn{2}{|c|}{ Cuantitativos } & \multicolumn{4}{|c|}{ Cualitativos } \\
\hline $\begin{array}{l}\text { Ficha } \\
\text { indicadores de } \\
\text { evaluación }\end{array}$ & $\begin{array}{l}\text { Ficha } \\
\text { indicadores } \\
\text { jurídicos }\end{array}$ & \multicolumn{2}{|c|}{$\begin{array}{l}\text { APP } \\
(\text { Mujeres }=85) \\
(\text { NNA }=95)\end{array}$} & \multirow[t]{2}{*}{$\begin{array}{l}\text { Documentos } \\
\text { varios }\end{array}$} & \multirow[t]{2}{*}{$\begin{array}{l}\text { Entrevistas } \\
(\mathrm{n}=44)\end{array}$} \\
\hline \multirow[t]{3}{*}{$\begin{array}{l}\text { Mujeres } \\
(n=85)\end{array}$} & \multirow[t]{3}{*}{$\begin{array}{l}\text { Mujeres } \\
(\mathrm{n}=85)\end{array}$} & $\begin{array}{l}\text { Agenda } \\
(\mathrm{n}=762)\end{array}$ & $\begin{array}{l}\text { PII } \\
(\mathrm{n}=85)\end{array}$ & & \\
\hline & & \multirow[t]{4}{*}{$\begin{array}{l}\text { Muestra } \\
(\mathrm{n}=154)\end{array}$} & \multirow[t]{2}{*}{$\begin{array}{l}\text { Entrevistas } \\
\text { iniciales } \\
(\mathrm{n}=85)\end{array}$} & \multirow[t]{2}{*}{$\begin{array}{lr}\text { Cuadrante } & \text { de } \\
\text { entradas } & y \\
\text { salidas } & \end{array}$} & $\begin{array}{l}\text { Grupo } \\
\text { motor } \\
(\mathrm{n}=3)\end{array}$ \\
\hline & & & & & $\begin{array}{l}\text { Personal } \\
(\mathrm{n}=8) \\
\text { Expersonal } \\
(\mathrm{n}=4)\end{array}$ \\
\hline \multirow[t]{2}{*}{$\begin{array}{l}\text { NNA } \\
(n=95)\end{array}$} & \multirow[t]{2}{*}{$\begin{array}{l}\text { NNA } \\
(\mathrm{n}=95)\end{array}$} & & \multirow[t]{2}{*}{$\begin{array}{l}\text { Entrevistas } \\
\text { finales } \\
(\mathrm{n}=40)\end{array}$} & $\begin{array}{l}\text { Casos de } \\
\text { reagrupación de } \\
\text { menores }\end{array}$ & $\begin{array}{l}\text { Red } \\
(n=22)\end{array}$ \\
\hline & & & & $\begin{array}{l}\text { Informes } \\
\text { Fundación Uría }\end{array}$ & $\begin{array}{l}\text { Agentes } \\
\text { clave } \\
(n=7)\end{array}$ \\
\hline
\end{tabular}

Fuente: elaboración propia.

Las fuentes de datos cualitativas (agendas diarias, entrevistas iniciales y finales) fueron tratadas a partir de un análisis de contenido y temático ${ }^{9}$. Se utilizó el programa informático Atlas.ti, que permite realizar análisis cualitativos a través de la organización y codificación de la información, así como el establecimiento de relaciones, la identificación de patrones y la cuantificación de su frecuencia ${ }^{10}$. El proceso de análisis de las distintas fuentes cualitativas fue similar. En primer lugar, el equipo evaluador elaboró una lista de códigos que permitieron una primera aproximación a los datos. En segundo lugar, se organizó la información contenida en las fuentes y se clasificó según los códigos generales. Posteriormente, se realizó un segundo análisis sobre la información codificada con la intención de identificar características comunes que permitan asignar códigos más específicos. En tercer lugar, cuando fue posible, y con el objetivo de presentar los resultados obtenidos de manera más clara, se procedió a cuantificar la frecuencia de los códigos analizados, es decir, el número de veces que aparecían en las fuentes analizadas. Este ejercicio permitió identificar, por ejemplo, las rutas más utilizadas por las mujeres para llegar a España o las razones que las motivaron a emigrar, presentes en los PII.

\footnotetext{
${ }^{9}$ VAISMORANDI, M., TURUNEN, H., \& BONDAS, T. (2013). Content analysis and thematic analysis: Implications for conducting a qualitative descriptive study. Nursing \& Health Sciences, 15, 398-405. https://doi.org/10.1111/nhs.12048
}

${ }^{10}$ FRIESE, S. (2019). Qualitative Data Analysis with ATLAS.ti (3 edition). Sage. 
La evaluación se ha encontrado con algunas limitaciones o dificultades metodológicas. Se analizaron los cuatro tipos de herramientas utilizadas por el equipo de intervención del programa ÖDOS, cada una de ellas con un formato diferente y cantidad de información distinta. Esta diversidad de las herramientas de recolección de datos dificultó el análisis, principalmente, por dos motivos. En primer lugar, por la falta de registro de información. Durante el análisis de los datos se encontraron apartados incompletos o, incluso, sin ningún tipo de información. De hecho, el equipo evaluador tuvo que acudir a La Muela para recopilar datos ausentes de cada una de las 85 mujeres atendidas por el programa. En segundo lugar, por la falta de sistematización de la información, lo que obligó al equipo evaluador, nuevamente, a buscar y contrastar los datos requeridos para articular los resultados. Estas dificultades supusieron una carga de trabajo importante y, si bien no ha sido posible analizar toda la información registrada por el programa, esta denota un gran potencial de cara a su explotación analítica.

Con todo, se lograron realizar análisis cualitativos y cuantitativos de la información recogida en la entrevista inicial con la mujer y la ficha de indicadores de evaluación. Las entrevistas sirvieron para profundizar en el análisis de los datos. Una vez obtenidos los resultados preliminares de los análisis cuantitativos y cualitativos por parte del equipo evaluador, este reunió al equipo motor y al personal del recurso residencial La Muela para compartir los resultados y debatir su interpretación. En el intercambio de información, que se llevó a cabo durante toda una mañana, se completó de manera participativa la evaluación del programa y se ilustró sobre los puntos fuertes y débiles del mismo. Esta misma dinámica se realizó con los miembros de la fase II. Estas reuniones sirvieron como un espacio de formación y reflexión conjunta, contribuyendo a la evolución del programa.

\section{RESULTADOS SOBRE LA EFICACIA DEL PROGRAMA}

El programa ÖDOS pretendía alcanzar dos objetivos: (1) prevenir la trata con fines de explotación sexual de mujeres africanas llegadas a las costas andaluzas con NNA a su cargo; y (2) proteger a esa infancia acompañada en movilidad. Durante el desarrollo del programa, ÖDOS incorporó un nuevo objetivo al ir conociendo las características de las mujeres que atendían: (3) detectar vulnerabilidades susceptibles de protección internacional.

\subsection{Alcance del programa y perfil de la población diana}

La eficacia del programa según esos objetivos tiene que ver, en primer lugar, con el alcance que haya tenido sobre la población diana. El número de mujeres que llegan a las costas andaluzas víctimas o potenciales víctimas de trata es una cifra negra cuyo tamaño no se ha estimado. Oficialmente no se contabiliza el número total de mujeres africanas con NNA que llegan a las costas españolas. Una aproximación al número de ellas es a través del número de menores subsaharianos acompañados llegados a las costas en patera o embarcaciones similares. Este dato es registrado por el Ministerio del Interior en el Registro Central de Menores Extranjeros no Acompañados (RMENA). Según esos datos oficiales (Portal de trasparencia, Ministerio del Interior), el programa ÖDOS ha alcanzado a una media de $10,3 \%$ de todos los menores subsaharianos acompañados llegados a 
Andalucía entre mayo de 2018 y marzo de 2020. Solo en 2019 pudo desplegarse el programa durante los 12 meses, siendo este año la mejor referencia para conocer la cobertura del programa, aún incipiente, que alcanzó el 19,4\% de los NNA acompañados.

La media de edad de las mujeres atendidas por el programa ÖDOS es de 27,7 años. La mayoría proviene de Costa de Marfil $(54,1 \%)$ y Guinea Conakry $(28,2 \%)$, dos de los países que empiezan a configurarse como el epicentro de las nuevas redes de trata ${ }^{11}$. Según la Fiscalía General del Estado (2019), los casos registrados hasta 2017 de trata con fines de explotación sexual africana eran exclusivamente sobre mujeres nigerianas $(\mathrm{n}=$ 135) y marroquís $(n=7)$; no obstante, a partir de ese año se incoaron casos referidos a trata procedente de Guinea Conakry (en 2017), de Guinea Ecuatorial y de Costa de Marfil (en 2018). En tal sentido, empieza a aflorar en la realidad judicial la victimización de mujeres explotadas sexualmente de otras procedencias diferentes a las nigerianas, que además coincide con el origen de las mujeres que han estado llegando a La Muela.

Tabla 3: Edad de las mujeres atendidas

\begin{tabular}{|l|l|}
\hline 18 a 20 años & $8 \%$ \\
\hline 21 a 25 años & $25 \%$ \\
\hline 26 a 30 años & $36 \%$ \\
\hline 31 a 35 años & $16 \%$ \\
\hline 36 a 40 años & $11 \%$ \\
\hline 41 años o más & $4 \%$ \\
\hline
\end{tabular}

Fuente: Ficha de indicadores de evaluación

Tabla 4: País de procedencia de las mujeres atendidas

\begin{tabular}{|l|l|}
\hline Marruecos & $5,9 \%$ \\
\hline Mali & $2,4 \%$ \\
\hline Guinea Conakry & $28,1 \%$ \\
\hline Costa del Marfil & $54,1 \%$ \\
\hline Togo & $1,2 \%$ \\
\hline Nigeria & $1,2 \%$ \\
\hline Camerún & $5,9 \%$ \\
\hline República democrática del Congo & $1,2 \%$ \\
\hline
\end{tabular}

Fuente: Ficha de indicadores de evaluación

Un 24\% de las mujeres atendidas por ÖDOS afirmó que emigra a Europa para evitar la mutilación genital femenina de sus hijas. Estas, junto con el 13\% de mujeres que habrían sido víctimas de violencia de género y el $11 \%$ que habrían huido por ser víctimas de un

\footnotetext{
${ }^{11}$ FISCALÍA GENERAL DEL ESTADO (2019). Ob. Cit.
} 
matrimonio forzado, representan un grupo importante de mujeres posibles solicitantes de protección internacional.

Gráfico 1: Motivos para emigrar de la mujer

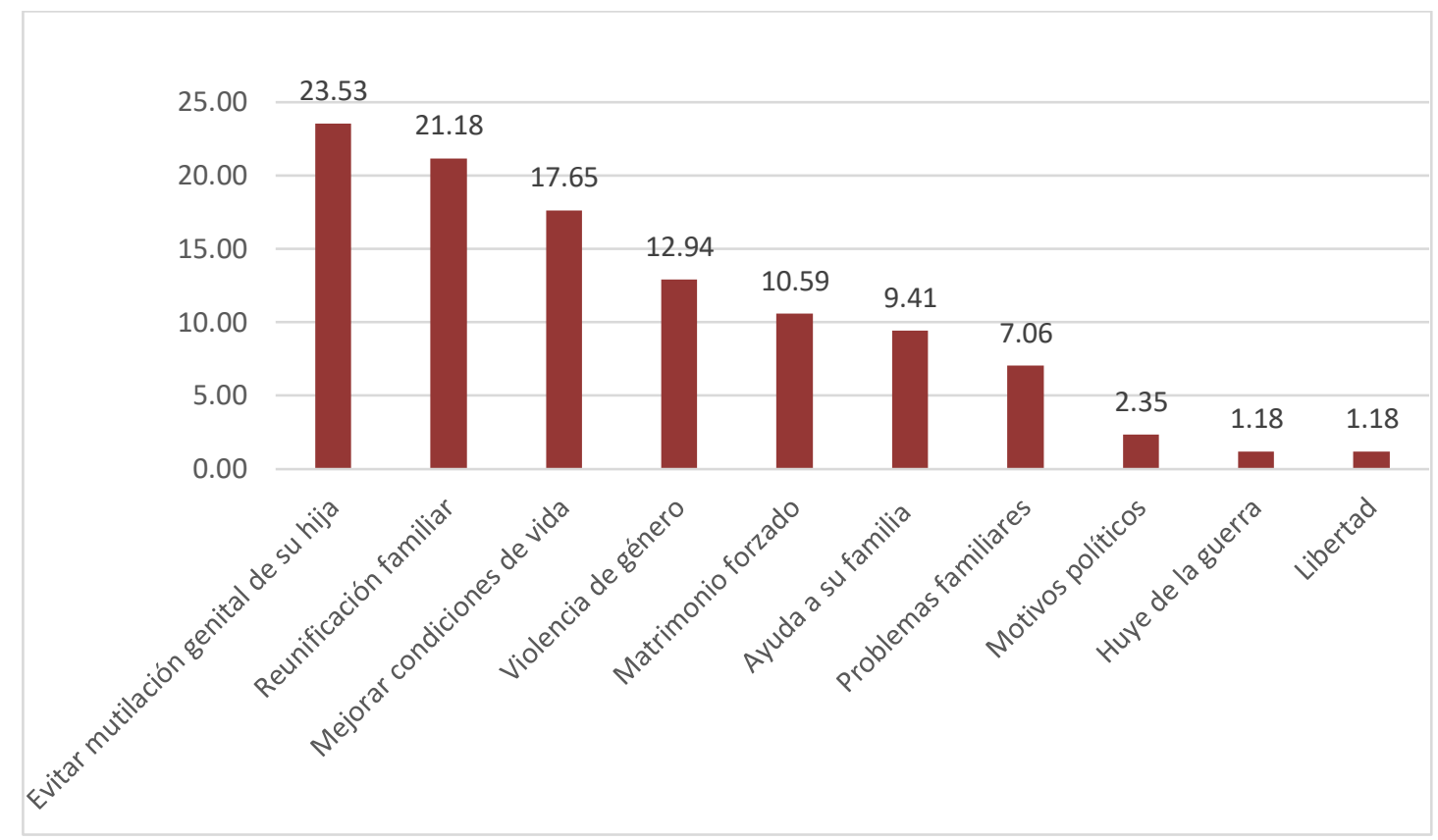

Fuente: Proyecto de intervención individual - Entrevista inicial

La mayoría (70\%) cruza dos fronteras o más durante su trayecto migratorio hasta España, algunas incluso cuatro, con los riesgos victimológicos que ello conlleva tales como extorsiones o agresiones de toda índole. En muchas ocasiones es difícil para estas mujeres expresar la victimización sufrida en el camino ${ }^{12}$, de modo que solo se registraron datos de victimización en el trayecto de 13 de ellas, quienes refirieron haber padecido en su mayoría robo, agresión física o violación.

${ }^{12}$ ECHEBURÚ, E. y AMOR, P.J. (2019). Memoria traumática: estrategias de afrontamiento adaptativas e inadaptativas. Terapia Psicológica, Vo. 37, nº 1. 
Figura 1: Rutas más frecuentes desde el país de origen hasta España

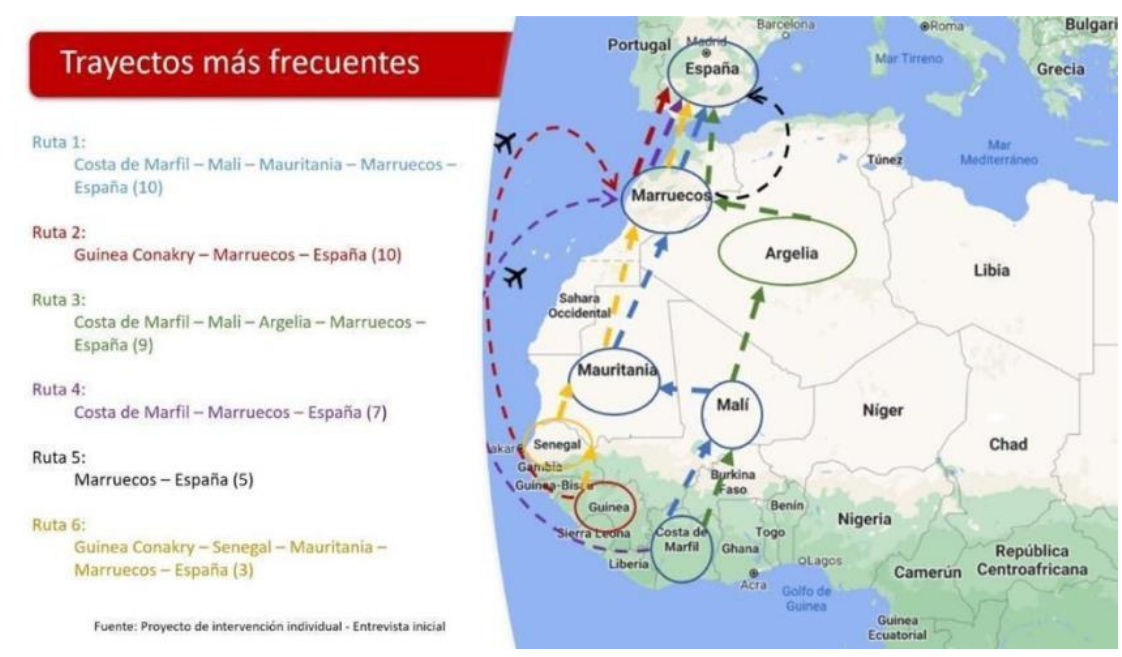

Fuente: Proyecto de intervención individual - Entrevista inicial

Al menos el $77 \%$ de las mujeres ha afirmado que pasó por el bosque de Nador (Marruecos) antes de cruzar a España. Las mujeres suelen describir la estancia en el bosque como una experiencia muy dura, aunque no suelen dar detalles de su situación ni la de sus hijos e hijas en este contexto. La Delegación Diocesana de Migraciones es un socio estratégico en Nador, ya que la mayoría de las mujeres refiere haber recibido su ayuda o asistencia durante su paso por el bosque.

El programa ÖDOS atendió a 95 NNA, la mayoría (65,3\%) con 5 años o menos, algunos de estos nacieron por el camino. Casi $60 \%$ son niñas, lo que puede relacionarse con el hecho de que las madres emigraran para evitar que las mutilaran genitalmente. El 66\% de las niñas cuyas madres han sido mutiladas genitalmente tienen entre 1 y 5 años.

Tabla 5: Edad de los y las NNA atendidas

\begin{tabular}{|l|l|}
\hline Recién nacidos y hasta un año & $18 \%$ \\
\hline 2 a 5 años & $47 \%$ \\
\hline 6 a 10 años & $27 \%$ \\
\hline 11 a 17 años & $7 \%$ \\
\hline
\end{tabular}

Fuente: Ficha de indicadores y Proyecto de intervención individual - Entrevista inicial 
Tabla 6: País de procedencia de los y las NNA atendidas

\begin{tabular}{|l|l|}
\hline Costa de Marfil & $49 \%$ \\
\hline Eritrea & $1 \%$ \\
\hline Guinea Conakry & $21 \%$ \\
\hline Marruecos & $15 \%$ \\
\hline Camerún & $4 \%$ \\
\hline Senegal & $1 \%$ \\
\hline Mali & $3 \%$ \\
\hline Nigeria & $1 \%$ \\
\hline Togo & $1 \%$ \\
\hline España (Montilla) & $1 \%$ \\
\hline España (Granada) & $2 \%$ \\
\hline
\end{tabular}

Fuente: Ficha de indicadores y Proyecto de intervención individual - Entrevista inicial

Gráfico 2: Sexo de los y las NNA atendidas

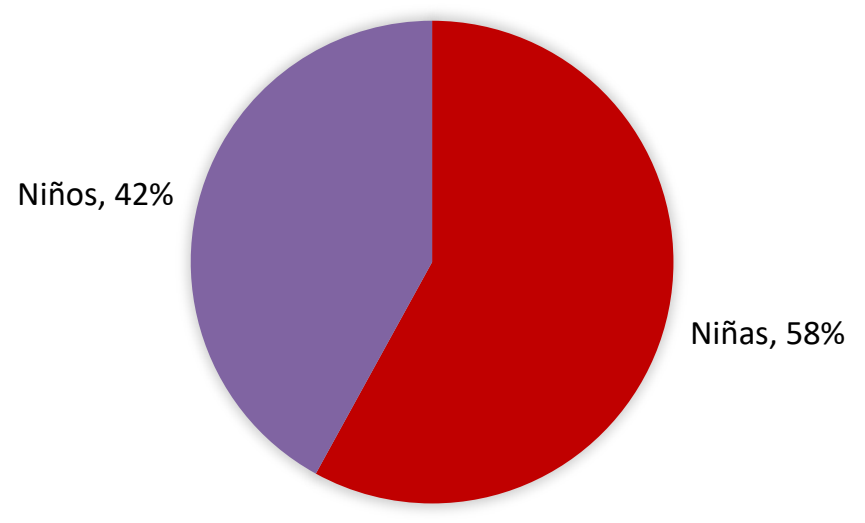

Fuente: Ficha de indicadores de evaluación

El equipo de intervención expresó en las entrevistas que los NNA sufrieron traumas y abusos durante el trayecto migratorio, lo que, unido a la falta de escolarización durante el trayecto, deriva en falta de habilidades sociales y presencia de actitudes agresivas, sobre todo en aquellos que pasan por el bosque de Nador. También contribuye a ello el hecho de que muchas mujeres no respondan adecuadamente al comportamiento disruptivo de los NNA al mostrarse indiferentes o infringir castigos severos. La falta de adecuadas 
estrategias educativas, la necesidad de prestar atención a la propia supervivencia durante el camino, el cansancio crónico con el que llegan, como veremos a continuación, suelen estar en la base de esas respuestas maternas.

\subsection{Eficacia según los objetivos del programa}

Una vez mostrados el alcance del programa con la población diana y las características de la muestra, se exponen los resultados sobre la eficacia del programa en relación con sus objetivos iniciales y sobrevenido.

A. Prevención secundaria de la trata con fines de explotación sexual

Con respecto a la prevención de la trata, el programa ÖDOS partía de la idea de que las mujeres serían conscientes de que estaban siendo víctimas de un delito de trata, esto es, que serían conocedoras de que estaban siendo conducidas a una situación de explotación según lo dispuesto en el artículo 177 bis del Código penal español y que, tras un periodo de restablecimiento de calidad en el recurso La Muela, serían capaces de reconocerse víctimas de trata. Sin embargo, ninguna de las mujeres atendidas por el programa en los dos primeros años de implementación se ha reconocido como tal.

Tres son los motivos que pueden llevar a que la mujer no se reconozca víctima de trata: Uno, que realmente no esté siendo tratada; dos, que esté siendo tratada, pero que tenga miedo a reconocerlo; $y$, tres, que no lo sepa porque esté siendo engañada. El engaño es el medio comisivo más frecuentemente utilizado por los tratantes en los casos conocidos por los tribunales españoles ${ }^{13}$. La víctima, que en un contexto migratorio es captada y transportada mediante engaño, no se percata del proceso conducente a la explotación en el que se encuentra ${ }^{14}$, y es por ello por lo que no puede reconocerse víctima de trata. En España, desde una perspectiva criminocéntrica o enfocada en la persecución del delito, solo las víctimas que se reconocen expresamente como tales son derivadas a recursos específicos para su protección.

El programa ÖDOS, orientado en la prevención secundaria de la trata (esto es, evitar su explotación sexual posterior) adoptó una perspectiva victimocéntrica en la medida en que decidió restablecer, proteger y acompañar a mujeres y NNA que aún no habían sufrido explotación sexual, y evitar que permanezcan o caigan en redes de trata.

Para identificar si el paso por La Muela cumple con el restablecimiento de las mujeres, el equipo de intervención registró una valoración del estado físico, del estado emocional y de la sensación de seguridad de cada mujer justo en el momento de llegar a La Muela y

\footnotetext{
${ }^{13}$ SALAT PAISAL, M. (2020). Análisis descriptivo de sentencias sobre trata de personas: Un estudio de casos judiciales entre 2011 y 2019. Revista Española De Investigación Criminológica, 18(1), 1-27. https://doi.org/10.46381/reic.v18i1.405;

${ }^{14}$ VILLACAMPA ESTIARTE, C. (2011). El delito de Trata de Seres Humanos: una incriminación dictada desde el derecho internacional. Aranzadi-Thomson Reuters.
} 
después, en el momento de su salida. La mayoría de las mujeres atendidas por el programa llega con dolores generalizados, desajustes del sueño y menstruales, agotamiento y dolor de cabeza. Solo el 6\% de las mujeres presentan enfermedades graves al llegar, como hepatitis, sarna o tuberculosis. Cuando la mujer abandona La Muela, los resultados muestran una mejora significativa del estado de salud, es decir, las enfermedades y trastornos físicos detectados a la llegada disminuyen en un alto porcentaje.

Gráfico 3: Estado de salud de las mujeres antes y después de La Muela

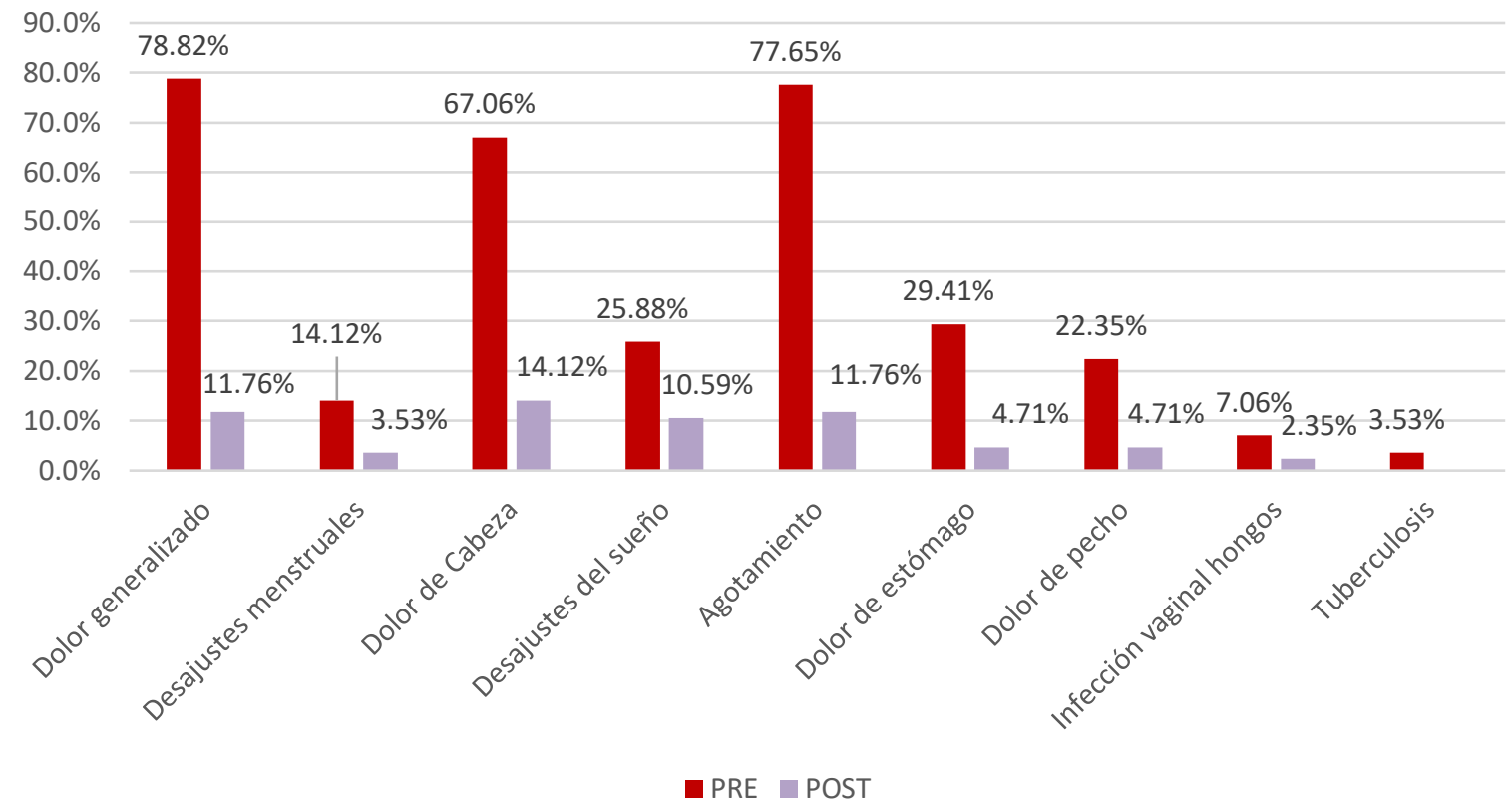

Fuente: Ficha de indicadores de evaluación

La misma mejoría se observa a nivel emocional. En las entrevistas, las educadoras sociales identifican que las mujeres, al llegar a La Muela, pasan mucho tiempo en la habitación aisladas y evadidas. Incluso el vínculo con sus hijos o hijas se observa debilitado, produciéndose situaciones en las que los niños y las niñas no están del todo atendidos por ellas. Pero, con el paso del tiempo, la mujer se va abriendo más, interviene con frecuencia en las dinámicas de la casa y participa en el grupo, se comunica más con el entorno y empieza a prestar una mayor atención a sus hijos o hijas. Lo mismo ocurre con la sensación de seguridad.

En el caso de los NNA los registros en la ficha de indicadores midieron la salud, la relación del menor con iguales y con adultos, la capacidad de atención y la actitud disruptiva. Todos esos aspectos mejoraban significativamente pasados unos meses en La Muela. 
Gráfica 4: Estado de salud de NNA antes y después de La Muela

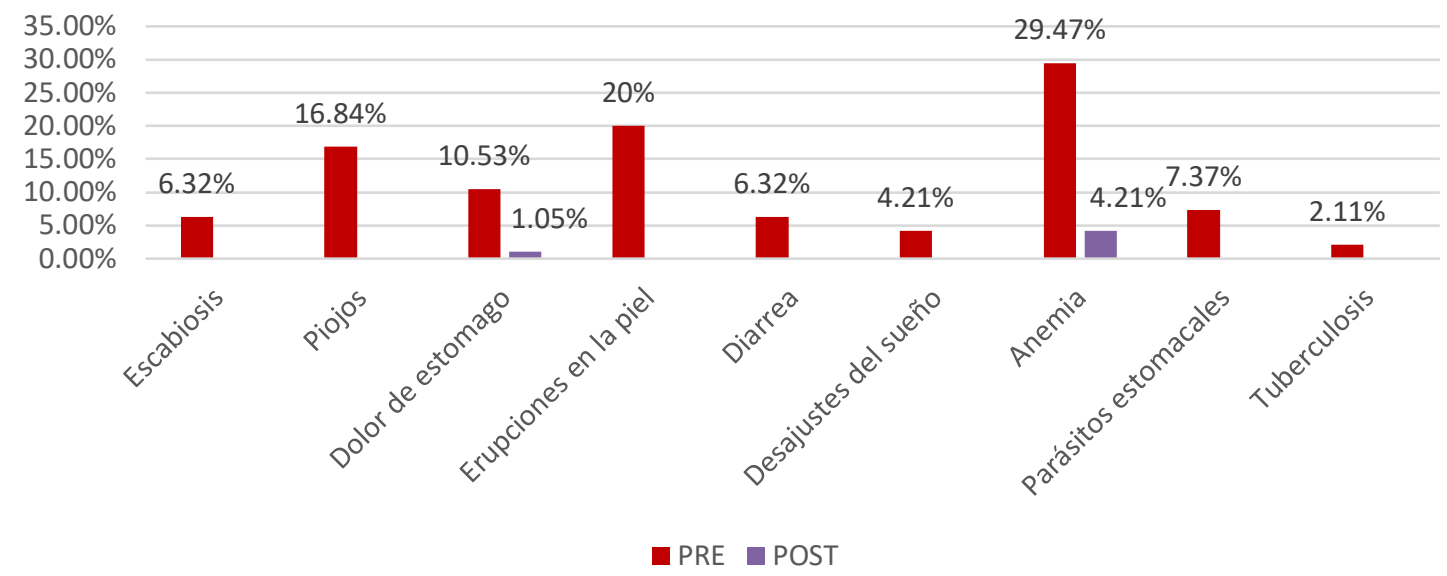

Fuente: Ficha de indicadores de evaluación

Todas las mediciones anteriores de las mujeres y los NNA relacionadas con el tiempo de permanencia en la Muela fueron sometidas a la prueba no paramétrica de Wilcoxon con la que se comprobó que la mejoría no era fruto del azar, sino del tiempo transcurrido en el recurso residencial La Muela (fase I), ya que todos los p-valor obtenidos fueron inferiores al nivel de significación $(\mathrm{p}<0,05)$.

La mayoría de las familias pasan entre 3 y 4 meses en La Muela. No obstante, durante los dos primeros años del programa, un $31 \%$ de las mujeres acompañadas de menores estuvieron menos de 3 meses, lo que dificultó implementar las estrategias de protección basadas en el restablecimiento e información. El porcentaje de mujeres que estuvo poco tiempo en La Muela es mayor al inicio del programa y disminuye casi hasta desaparecer en los últimos meses, observando una mejora en el programa desde una perspectiva evolutiva. 
Gráfica 5: Tiempo de permanencia de las familias en La Muela

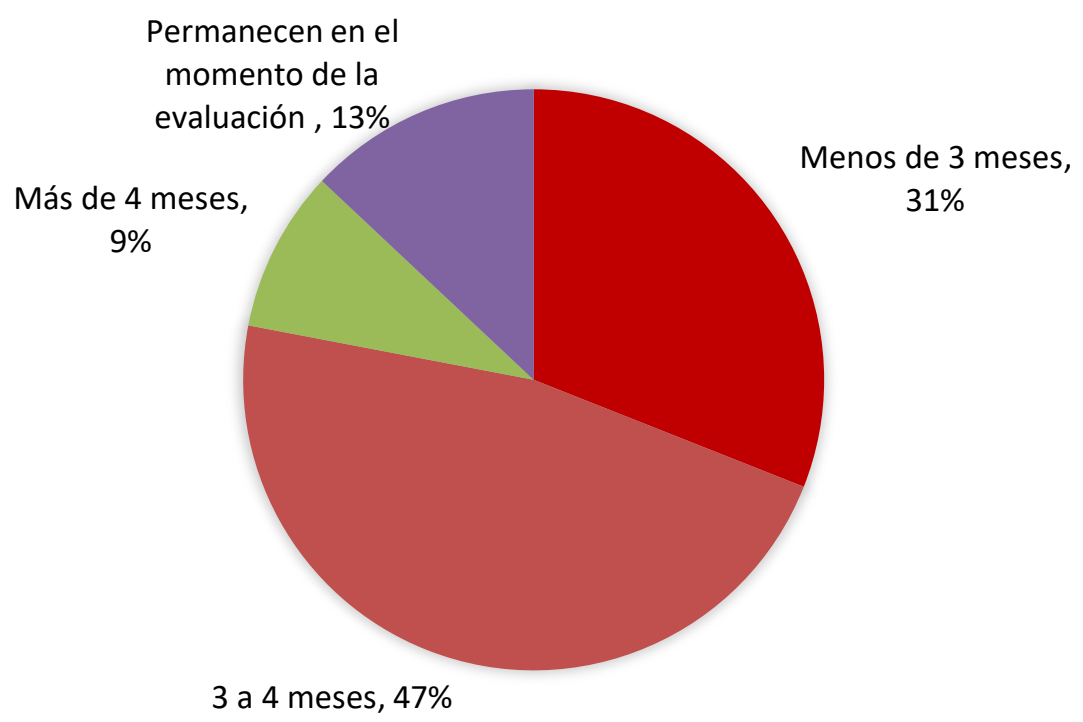

Fuente: Ficha de indicadores de evaluación

Parte de los objetivos de intervención en La Muela es la protección de las mujeres y NNA a su cargo una vez que abandonan ese recurso residencial. Para ello se busca dar información y formación a las mujeres para que conozcan su entorno y sean capaces de tomar decisiones por ellas mismas. El equipo de intervención valoró de 1 a 5 estos tres aspectos (véase gráfica 6) por cada mujer al llegar y al salir del recurso residencial La Muela. La media de estos valores permite visualizar la evolución experimentada en dichos aspectos. A la llegada, las mujeres tenían una media de 1,5 de conocimiento del entorno $\mathrm{y}$ de información (bajo), mientras que a la salida se observa un aumento claro en estos aspectos. No ocurre lo mismo en el caso de la "dependencia de las decisiones de otros", en donde el resultado al llegar y salir del recurso residencial se mantiene en 4 (alta dependencia). Es frecuente que ese otro sea un hombre ${ }^{15}$. Como argumenta MONTIEL ${ }^{16}$ la dependencia emocional, usando la seducción junto a la oferta de ayuda económica en el país de destino, suele ser el modus operandi en la modalidad de engaño del delito de trata. De ahí que la dependencia que mantienen con la persona de contacto en el país de destino pueda ser un indicador del riesgo que corre la mujer.

\footnotetext{
${ }^{15}$ THILL, M. y GIMÉNEZ ARMENTIA, P. (2016). El enfoque de género: Un requisito necesario para el abordaje de la trata de seres humanos con fines de explotación sexual. Revista Europea de Derechos Fundamentales, 27, 439-459
}

${ }^{16}$ MONTIEL TORRES, O. (2009). Trata de personas: padrotes, iniciación y modus operandi. México: Instituto Nacional de las Mujeres. 
Gráfica 6: Dimensión de protección

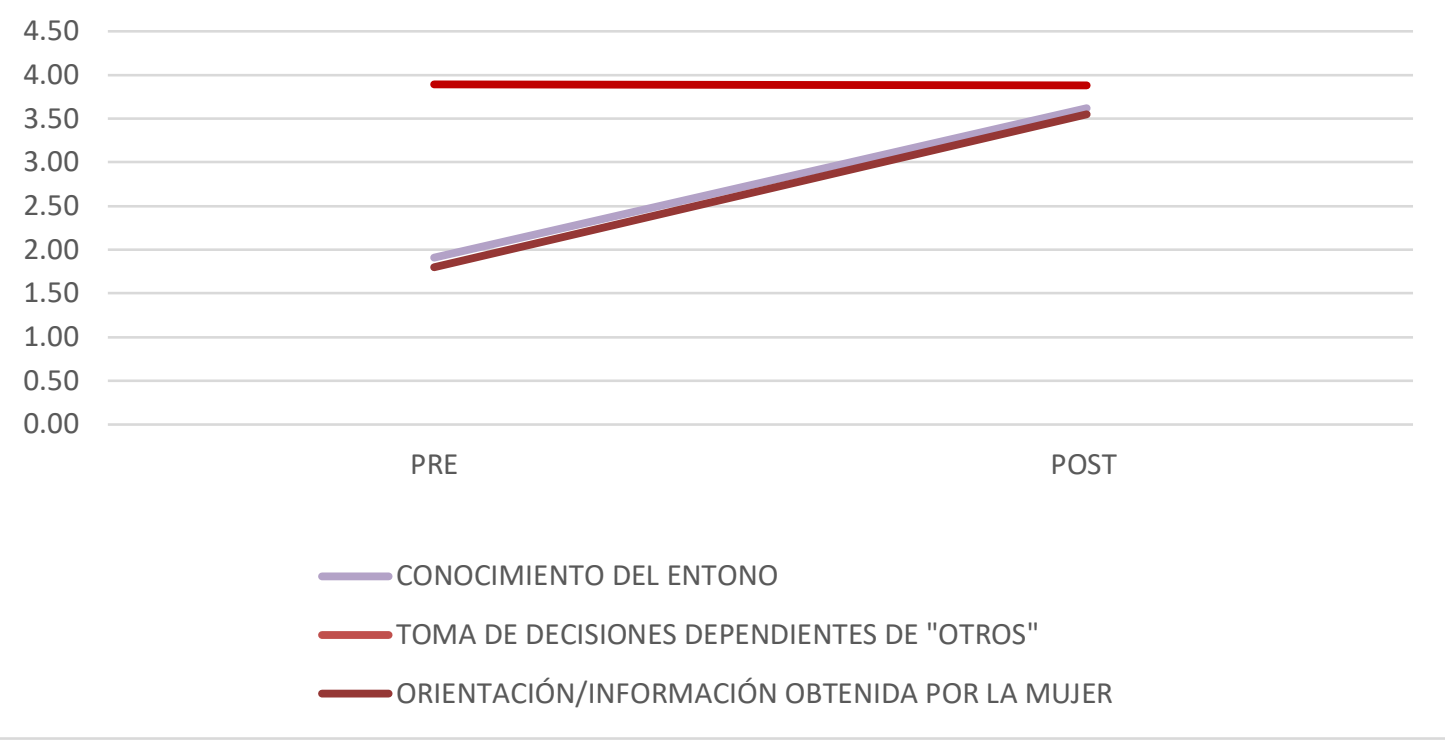

Fuente: Ficha de indicadores de evaluación

Por otro lado, también se evaluó, en la ficha de indicadores, la toma de conciencia de la usuaria sobre sus derechos; la vinculación entre la mujer y el/la menor con que entra la usuaria al recurso. Además, se valoró el reajuste de las expectativas de las mujeres respecto de su llegada a Europa con la idea de desmitificar las ideas preconcebidas sobre las posibilidades en España y Europa; y el equipo de intervención en La Muela como referente para las usuarias. Estos indicadores conforman la dimensión de acompañamiento, central para el programa ÖDOS y poco habitual entre las distintas instituciones que en España asisten a víctimas de trata ${ }^{17}$. Para la evaluación de esta dimensión, se calculó la media aritmética en todas las variables en el momento de entrada (pre-) y de salida (post-) de las mujeres de La Muela. En todos los casos se observa un aumento importante al final. Por ejemplo, el equipo de intervención valora que las mujeres tenían mayor vínculo con sus hijos/as al momento de abandonar La Muela, asimismo consideraban que sus expectativas se ajustaban más a la realidad.

${ }^{17}$ VILLACAMPA ESTIARTE, C. y TORRES FERRER, C. (2021). Aproximación institucional a la trata de seres humanos en España: Valoración crítica. Estudios penales y Criminológicos. Vol. XLI 
Gráfico 7: Dimensión acompañamiento

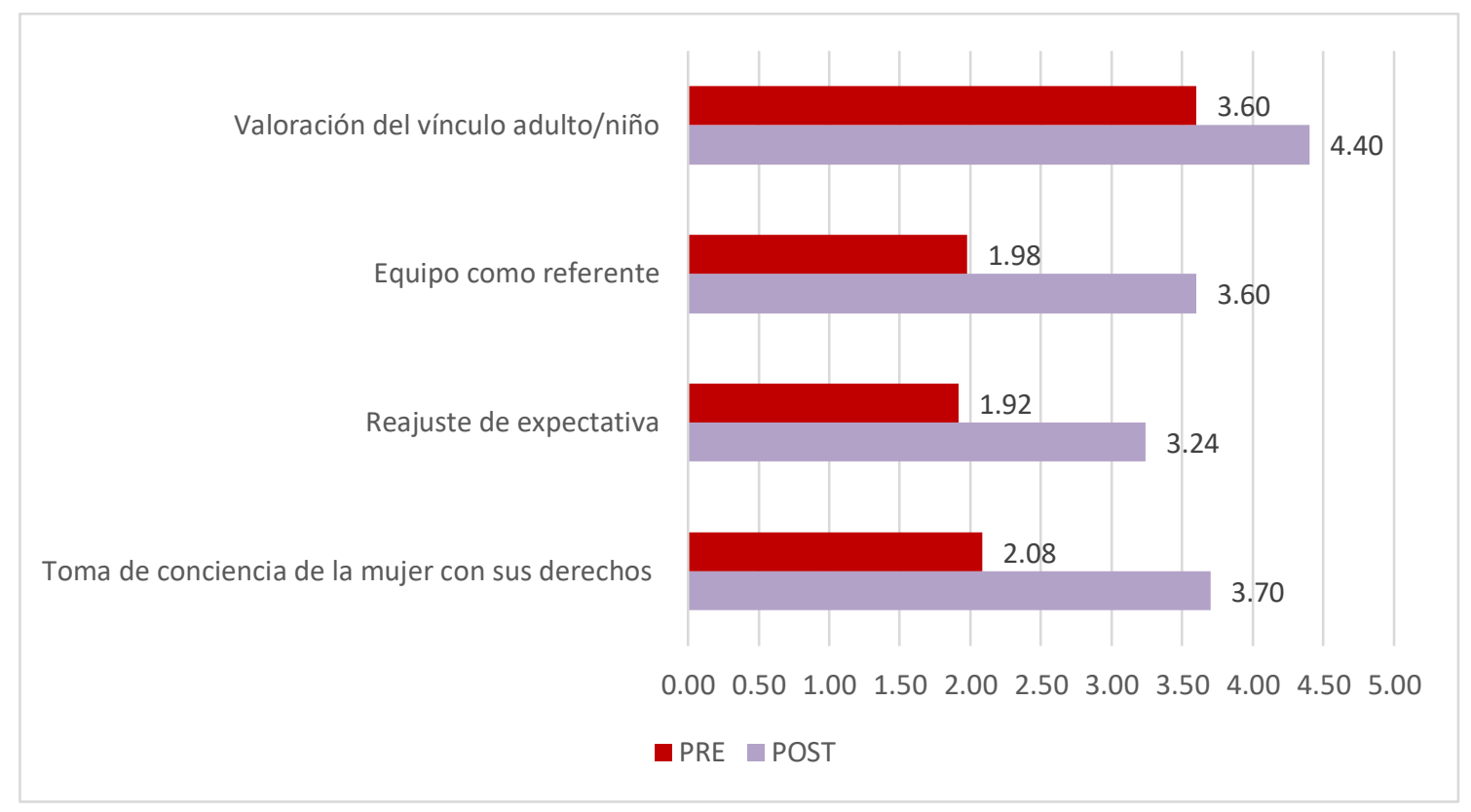

Fuente: Ficha de indicadores de evaluación

Respecto a la continuidad entre fase I y fase II del programa, durante los dos primeros años sólo el 13,5\% de las usuarias fueron derivadas a fase II. Del resto (86,5\%), el 90\% continuó su proceso migratorio, el $5 \%$ se fugó y el resto no cumplía con el perfil del recurso. En este caso, teniendo como base que el recurso de La Muela fue creado con la intención de que las mujeres pasaran a una segunda fase, como una alternativa a su proyecto migratorio incierto y, debido a que eso solo se ha conseguido en un porcentaje bajo de usuarias, la eficacia en este sentido es muy mejorable.

Gráfico 8. Lugar de derivación de las familias

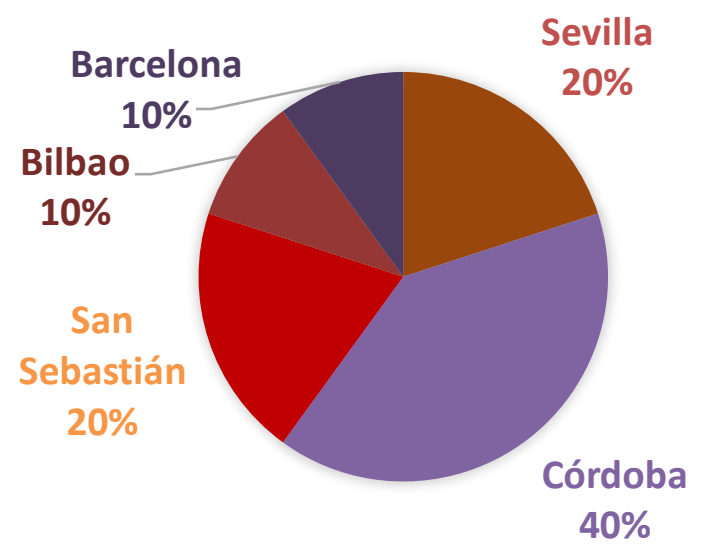

Fuente: Cuadrante de seguimiento 
La mayoría fue derivada a un recurso de la Red ÖDOS (80\%) y el resto a recursos para solicitantes de protección internacional. Se ha detectado que en un $40 \%$ de los casos se ha tardado más de tres meses desde que se solicita la derivación por parte de fase I hasta que se hace efectiva en algún recurso de la fase II. Al igual que en otros indicadores, el programa ha ido mejorando en este aspecto y cada vez el porcentaje anterior es menor. No obstante, el retraso en las derivaciones produce efectos contraproducentes en las mujeres, como la sensación de estancamiento e impaciencia. El recurso residencial La Muela se encuentra en una localidad alejada de la ciudad y por eso se configura como un lugar ideal de parada para el restablecimiento y reflexión, pero no es el sitio idóneo para estancias a largo plazo de familias como las que atiende el programa ÖDOS. Las mujeres que deciden quedarse en España buscan trabajar y empezar su proceso de integración. La derivación a otros recursos residenciales es parte de ese proceso y no debe tardar tanto tiempo en producirse.

Gráfico 9: Tiempo de permanencia en fase II

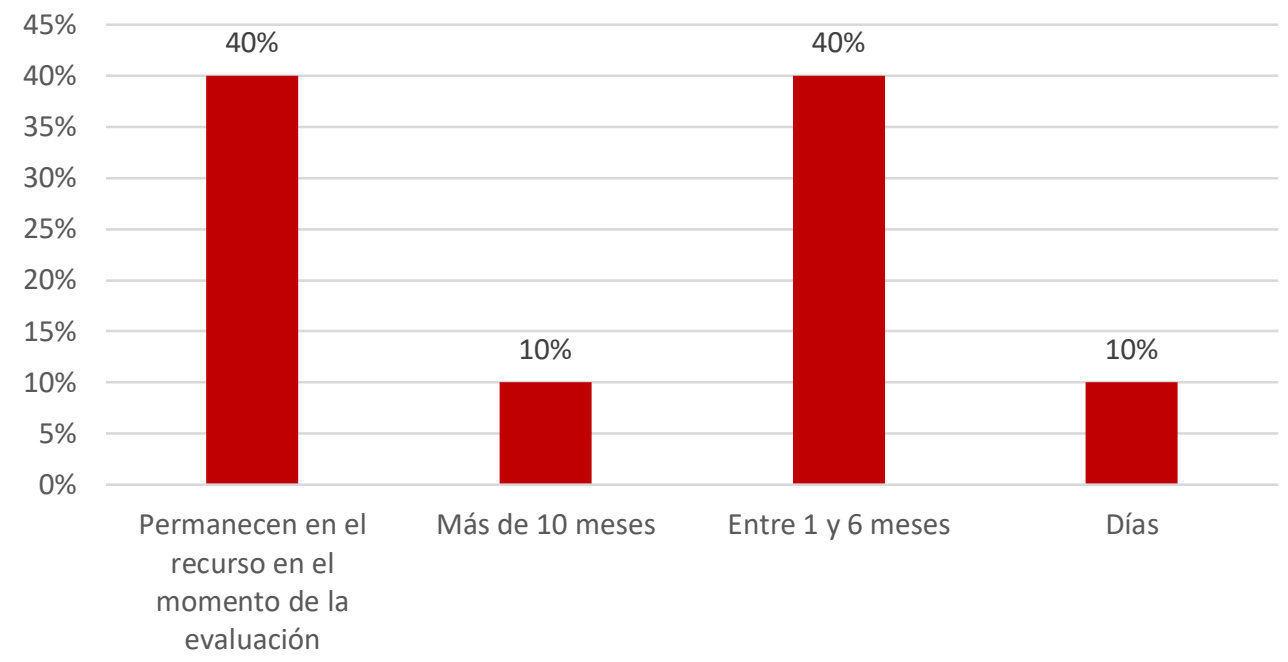

Fuente: Ficha de indicadores de evaluación

Respecto a la permanencia en la fase II, de las pocas mujeres derivadas, un alto porcentaje de ellas abandonó el recurso durante los primeros seis meses y continuó su trayecto migratorio. Este dato, junto con el alto porcentaje de mujeres que no llegan a ser derivadas a fase II, pone de relieve la importancia del seguimiento que este programa debe realizar con las mujeres una vez que salen de su programa. Varios son los motivos que justifican la importancia del seguimiento: 1) brindar un tejido de contactos activos en caso de que la mujer supuestamente engañada por una red de trata se encuentre en una situación de explotación de la que desea escapar y 2) tomar el pulso al verdadero riesgo que estas mujeres corren al llegar a sus destinos y así evaluar el impacto del programa.

Con respecto al seguimiento de las usuarias no derivadas $(86,5 \%$ del total de mujeres atendidas), la mayoría continuó su proceso migratorio a Francia (46,38\%) y un $12 \%$ de ellas continúa en España, donde se ha encontrado con un familiar. Además, con el 64,06\% 
$(\mathrm{n}=41)$ de las no derivadas se ha mantenido un contacto informal que en el 27,91\% de los casos duró más de seis meses. Sin embargo, un 15,6\% de las usuarias sólo contactó con alguien del equipo de intervención del programa tres días después de su salida de La Muela, tras lo cual fue imposible localizarlas nuevamente.

B. Protección de la infancia acompañada en movilidad

El enfoque de infancia del programa ÖDOS es fundamental porque, si bien las mujeres forman un colectivo invisible, más aún lo son las/os NNA que las acompañan. Actualmente, las movilidades que afectan a NNA siguen siendo invisibles para la sociedad y para las administraciones responsables de su protección como veremos a continuación. Esta invisibilidad tiene como principal consecuencia la vulneración de sus derechos ${ }^{18}$.

Algunos nacen por el camino. En muchas ocasiones no queda constancia registral de este hecho. Por tal motivo, los menores nacidos en tránsito son invisibles y quedan a la sombra de cualquier derecho en la medida en que se le niega su derecho a la identidad. Sin identidad no hay reconocimiento de derechos, quedando totalmente ocultos para el sistema. También se hace difícil el reconocimiento de la nacionalidad, lo que lleva a que estos/as menores sean de facto o funcionalmente apátridas ${ }^{19}$.

Por otro lado, la política pública española está diseñada para que, en los supuestos de mujeres que inmigran irregularmente acompañadas de menores, se produzca una separación entre ellos al llegar a territorio español hasta que se confirme la filiación a través de los resultados del $\mathrm{ADN}^{20}$. Sin embargo, esta práctica de separaciones automáticas es contraria a la doctrina del Tribunal Europeo de Derechos Humanos (TEDH) que vela por la unidad familiar como principio básico a considerar (caso R.M.S c. España, número 28775/94, 18 de junio de 2013). El programa ÖDOS se propone como reto, en todos los casos de mujeres migrantes que llegan con menores a las costas andaluzas, mantener el vínculo entre ambos, aun cuando algunas pocas mujeres llegan acompañadas de NNA que no son sus hijos/as (véase tabla 7).

\footnotetext{
${ }^{18}$ BHABHA, J. (2009). Arendt's Children: Do today's Migrant Children have the Right to have Rights? Humans Rights Quaterly, 31, 410-451.

${ }^{19}$ BHABHA, J. (2009). Ob. Cit.

20 SÁNCHEZ TOMÁS, J. (2020). Mesa: La mujer migrante. VIII Cumbre de mujeres juristas. Ilustre colegio de abogados de Madrid. 29 y 30 de octubre. Recuperado de: https://www.youtube.com/watch?feature=youtu.be\&v=R2HVBOeZne4\&app=desktop
} 
Tabla 7: Resultados negativos de pruebas de ADN realizadas a mujeres y menores en costas

\begin{tabular}{|l|l|l|l|}
\hline Año & Pruebas realizadas & Resultados negativos & $\mathbf{\%}$ \\
\hline 2015 & 545 & 3 & 0,5 \\
\hline 2016 & 248 & 4 & 1,6 \\
\hline 2017 & 377 & 15 & 3,9 \\
\hline $2018^{*}$ & $377^{*}$ & $15^{*}$ & $3,9 *$ \\
\hline 2019 & 650 & 39 & 6 \\
\hline
\end{tabular}

*El dato se repite en las memorias de 2017 y 2018, debiendo ser una errata. Fuente: Memorias de la Fiscalía General del Estado de 2015 a 2019.

El programa ÖDOS se plantea, por tanto, varios objetivos con estos NNA en relación con lo anterior. Por una parte, evitar la separación traumática de la mujer que le acompaña, aun cuando la prueba de ADN sea negativa, siempre que el vínculo entre ambos sea positivo y la mujer constituya un adulto referente para el/la menor. Y, por otra parte, poner en valor los informes sociales que acreditan la necesidad de mantener el vínculo para que sea tomado en cuenta en el resto de las decisiones administrativas o judiciales con la idea de dar cumplimiento al principio del interés superior del NNA.

Los NNA que están acompañados de sus madres también son un motivo de preocupación desde la perspectiva de la protección de la infancia, ya que se encuentran en una situación clara de riesgo por su invisibilidad jurídica y por el entorno social incierto de destino. De hecho, mientras los menores extranjeros no acompañados son objeto de protección por parte de los servicios de infancia de las Comunidades autónomas, se supone que la infancia acompañada en movilidad está protegida en la medida en que su progenitor se hace cargo, quedando invisibilizadas en muchas ocasiones las situaciones de riesgo en las que se encuentra.

Es cierto que existe una figura jurídica conocida como "declaración de la situación de riesgo" para proteger a la infancia en movilidad acompañada. Sin embargo, está poco desarrollada en la intervención social y su uso con respecto a la infancia en movilidad es inexistente, pues la batería de indicadores de riesgo que se contemplan para materializar tal decreto no alberga los factores de riesgo específicos de estos menores ${ }^{21}$. Nuevamente su especial situación de vulnerabilidad queda invisibilizada para el sistema.

Por otra parte, los padecimientos de la mujer durante su trayecto migratorio llevan a esta a una situación de estrés postraumático que hace complicado que pueda encargarse de atender a su hijo/a como debiera. Por ello, junto al restablecimiento de la mujer, el trabajo

${ }^{21}$ ARCE JIMÉNEZ, E. (2019). Menores víctimas de trata. Revista Crítica Penal y Poder, 18, 278-296; MANZANEDO NOGUERUELA, C. (2019). Menores extranjeros acompañados. La problemática invisible de los niños y niñas migrantes acompañados que llegan a la frontera sur española. Revista Crítica Penal y Poder, 18. 260-266. 
dirigido a reforzar el vínculo materno-filial se antoja una estrategia primaria de protección a la infancia ${ }^{22}$.

El programa ÖDOS presenta propuestas pioneras ante esta realidad desconocida. Los resultados con respecto a la protección de esta infancia destacados en las entrevistas con el grupo motor y miembros del Ayuntamiento de Montilla (colaborador del programa y parte de la Red ÖDOS) son los siguientes:

La práctica administrativa habitual es negar el registro en el padrón municipal a personas en situación administrativa irregular. La buena coordinación de La Muela con el Ayuntamiento de Montilla ha posibilitado vencer la práctica vulneradora de derechos anterior una vez que la deportación no puede ser ejecutada y la mujer y los/las menores estén registrados por el Ministerio de Interior. El Ayuntamiento de Montilla, a partir de la petición del programa ÖDOS y de manera pionera en España, acepta la documentación proporcionada con los nombres y NIE de las mujeres y NNA para su registro en el padrón municipal, tornándoles visibles para el sistema y posibilitando el acceso a la tarjeta sanitaria y escolarización inmediata.

Además, el programa ÖDOS impulsó el desarrollo por parte del Ayuntamiento de Montilla del primer reglamento para la declaración de riesgo de menores acompañados en movilidad. A partir de la experiencia de trabajo conjunto, desde los servicios sociales se identifica que el procedimiento no se hace según se recoge en la legislación vigente (art. 17 de la Ley 26/2015, de 28 de julio, de modificación del sistema de protección a la infancia y a la adolescencia). Las declaraciones de riesgo se suelen hacer para determinar posteriormente el desamparo del NNA, sin que se diseñe un plan de intervención para corregir la situación de riesgo. Además, los indicadores de riesgo establecidos en la práctica, al menos en Andalucía, no tienen capacidad predictora del riesgo específico de los menores acompañados en movilidad. Esa constatación vino seguida de una propuesta alternativa por parte de los servicios sociales de Montilla: la elaboración de informes sobre la familia, donde se registra la situación de riesgo del NNA que necesita acompañamiento para que esa situación no se agrave y pueda derivar en desamparo. Una vez identificada la situación de riesgo, el Ayuntamiento de Montilla hace un esfuerzo de coordinación con los servicios sociales del ayuntamiento de las localidades hacia dónde va la familia al salir de La Muela para informarles de la situación de riesgo. Esa fue la fórmula de protección encontrada debido a las limitaciones existentes en los indicadores de riesgo actuales, así como por el factor tiempo que impide que se desarrolle el acompañamiento necesario cuando el riesgo es declarado.

Otro éxito importante del programa ÖDOS ha sido conseguir la reagrupación de menores en al menos 5 casos, ya que es parte fundamental de la protección de los menores situarse en su contexto familiar. Por el contrario, la falta de registro de los/las menores que han nacido por el camino y el riesgo de apatridia han sido una de las grandes dificultades del

${ }^{22}$ HELLINGER, B. (2000). Órdenes de amor. Ed; BARUDY, J. (1998). Los buenos tratos a la infancia. Parentalidad, apego y resiliencia. Ed. Gedisa. 
programa, lo que ha puesto de manifiesto la importancia de contar con una buena asistencia jurídica que derive en una completa protección de estos menores.

C. Detección de vulnerabilidades para solicitar protección internacional.

Este objetivo ha cobrado fuerza en un momento del programa en el que se perdió temporalmente la perspectiva victimocéntrica de la prevención de la trata. Al no poder demostrar que ÖDOS estaba sirviendo para la prevención de la trata debido a que ninguna mujer se identificaba como víctima de dicho delito, ni detectar, al mismo tiempo, vulnerabilidades de las mujeres y los NNA en sus países de origen y durante el trayecto migratorio, se planteó la posibilidad de dar un viraje en los objetivos y enfocarse hacia la protección internacional.

Para valorar el programa ÖDOS con respecto a este objetivo basta referirse al hecho de que el $24 \%$ de las mujeres afirma salir de su país por miedo a la mutilación genital (MGF) de sus hijas y que el $55 \%$ de las mujeres afirma haberlo sido. Hemos cruzado este dato con el número de mujeres que vienen acompañadas con sus hijas como indicador que pudiera justificar las solicitudes de protección internacional basadas en el miedo a que sus descendientes sufran mutilación genital. Los resultados son muy interesantes: El 70\% de las mujeres que sufrieron MGF vino acompañada de una menor (véanse figuras $11 \mathrm{y}$ 12), teniendo el $66 \%$ de esas menores entre 1 y 5 años.

Gráfico 10: Porcentaje de mujeres mutiladas genitalmente y mujeres mutiladas genitalmente que vienen acompañadas de al menos una hija

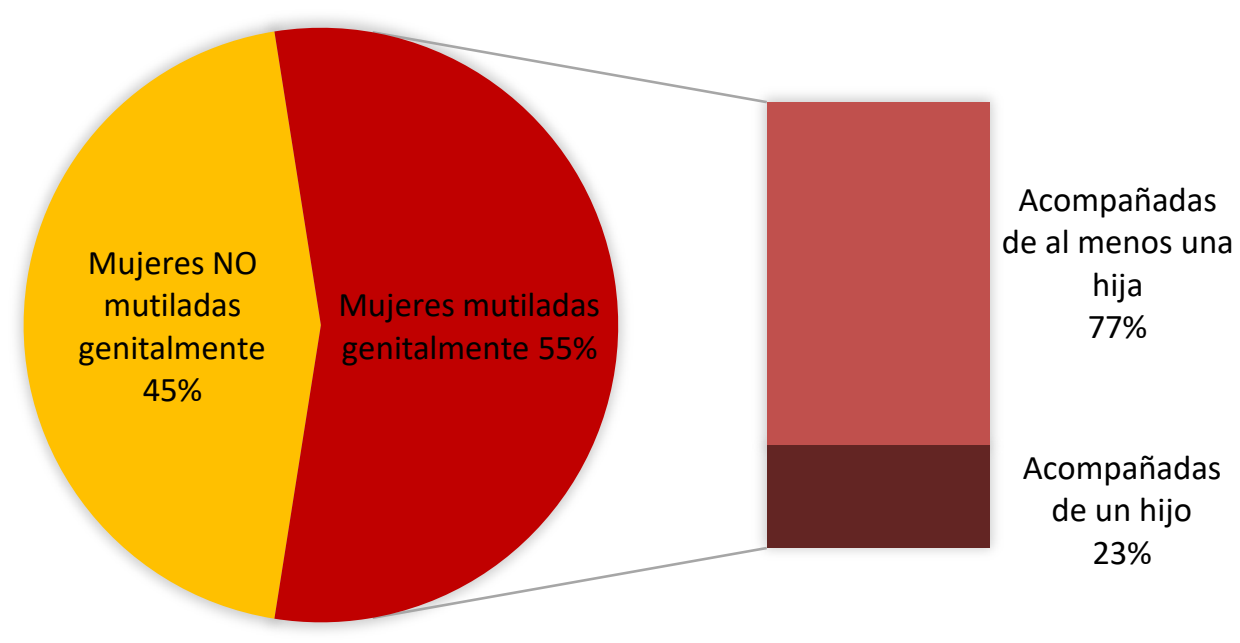

Fuente: Ficha de indicadores de evaluación

En el 9,6\% de los casos se ha solicitado la protección internacional de la usuaria y en un $4,2 \%$ se ha solicitado la protección internacional de los y las NNA. De estos últimos, en 
un solo caso se ha solicitado la protección internacional de la menor sin que estuviera adjunta a la solicitud de la mujer con la que entró al recurso.

Gráfico 11: Motivos solicitud protección internacional

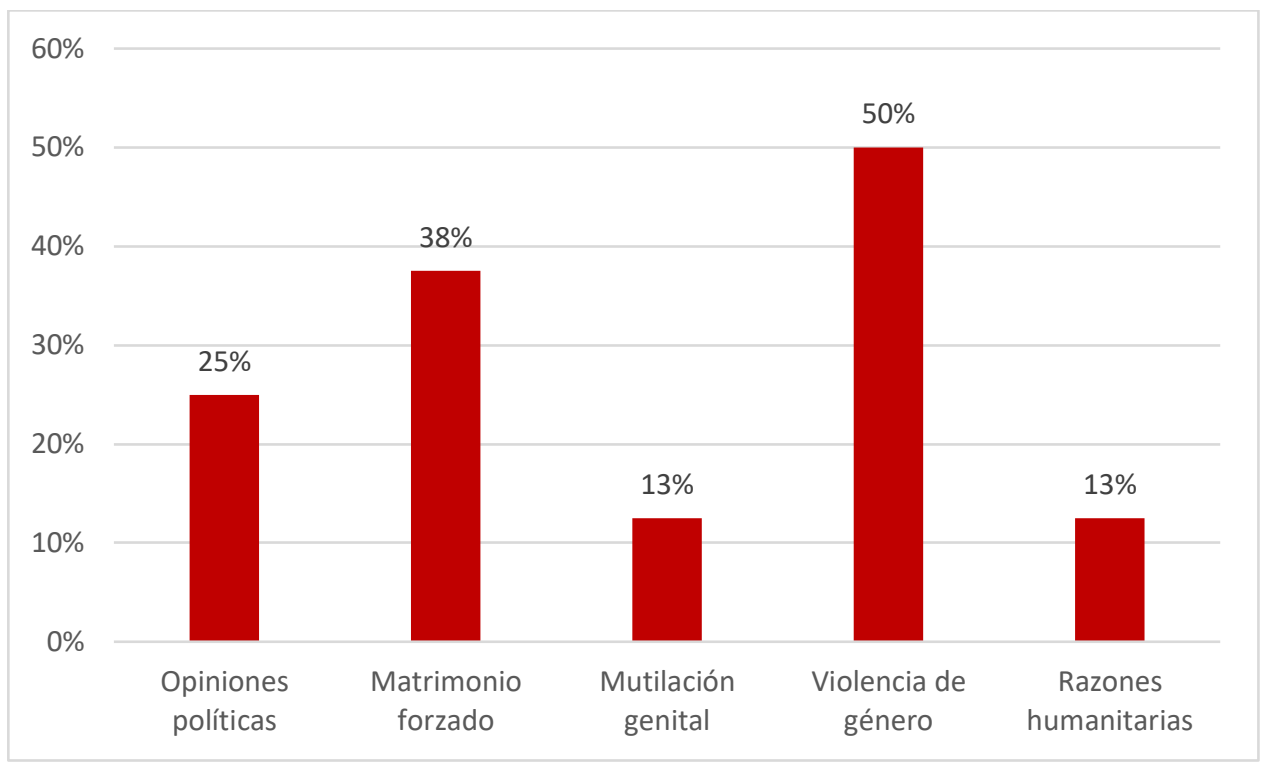

Fuente: Ficha de indicadores de evaluación

La mayoría de las solicitudes de protección internacional se han iniciado porque la mujer ha sufrido violencia de género o se le ha obligado a contraer matrimonio. Además, es necesario mencionar que en el 37,5\% de los casos de solicitud de protección internacional coincidían más de un motivo para solicitarla.

Gráfico 12: Estado de la solicitud de protección internacional

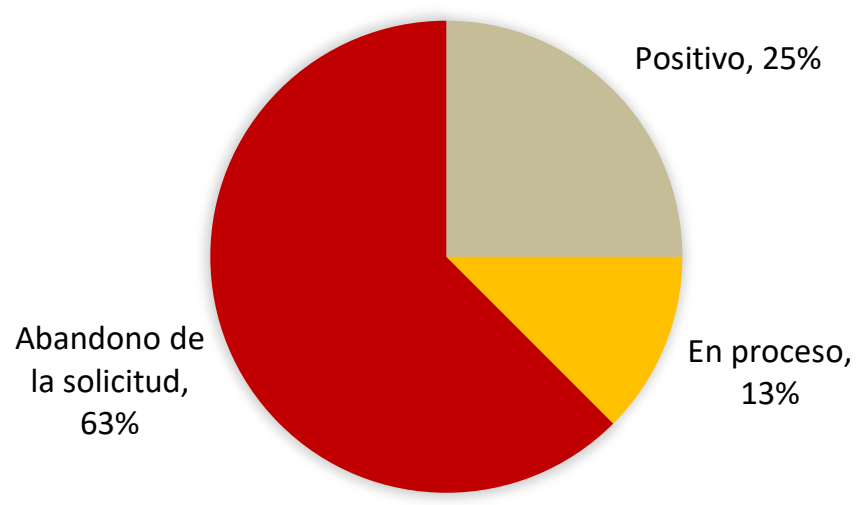

Fuente: Ficha de indicadores de evaluación 
El alto porcentaje de abandono de solicitudes de protección internacional se explica por el gran número de mujeres que dejan La Muela sin ser derivadas a segunda fase, o que incluso salen antes de tiempo de la segunda fase para continuar su proceso migratorio. Resulta muy satisfactorio que todas las solicitudes tramitadas hayan obtenido una resolución positiva, lo que muestra la buena labor de intervención jurídica que se está llevando a cabo desde el programa. Otro dato de interés es que el 75\% de las solicitantes han sido derivadas a segunda fase. Aunque no era el objetivo inicial del proyecto, los resultados muestran la necesidad de enfocar la atención también en la detección de vulnerabilidades.

\section{CONCLUSIONES}

Una de las conclusiones de este trabajo hace referencia a la falta de registro oficial de las mujeres migrantes que llegan a costas españolas acompañadas de NNA. Este es de por sí un indicador de la invisibilidad de este perfil de mujeres para el sistema español. No obstante, los menores que las acompañan si son inscritos en el Registro MENA. A partir de ese dato es posible hacer estimaciones sobre la población diana que llegan a las costas andaluzas y avanzar el dato de que el programa ha alcanzado casi a un $20 \%$ de dicha población. Este dato se muestra suficiente para que los resultados del programa ÖDOS sean tenidos en consideración de cara a consolidar una estrategia enfocada a la protección de mujeres migrantes acompañadas con NNA, visibilizar situaciones de vulnerabilidad y riesgo, y hacer incidencia encaminada a cambiar políticas públicas.

El programa ÖDOS es pionero en España en la prevención secundaria de la trata de personas con fines de explotación sexual desde una perspectiva victimocéntrica. El análisis de las variables de restablecimiento muestra que el programa ÖDOS es eficaz en relación con los NNA y las usuarias que pasan por el recurso residencial La Muela. Los resultados de esta intervención pueden llegar a ser eficaces para la prevención secundaria de la trata. Para ello el programa debe conseguir que las mujeres con indicios de trata que no se autoidentifican como tales y que tan solo quieren continuar su trayecto migratorio, permanezcan el mayor tiempo posible en La Muela. Esto es una dificultad del programa, que se une al hecho de que en la práctica sigue imperando una perspectiva criminocéntrica en esta materia. Aunque el art. 177 bis del Código Penal y el art. 59 bis de la Ley orgánica 4/2000, de 11 de enero, sobre derechos y libertades de los extranjeros en España y su integración social responden a una perspectiva victimocéntrica derivada de los requerimientos internacionales, la práctica parece desenvolverse de otra manera. Los indicios de trata no son suficientes para poner en marcha los mecanismos de protección. Estos en todo caso despegan cuando la mujer se autoidentifica víctima de trata. Esta práctica presenta muchas grietas como, por ejemplo, cuando hay engaño en el traslado, ocultando el proceso conducente a la explotación sexual con promesas migratorias exitosas. Posiblemente sean muchas las mujeres que consienten en un proceso migratorio irregular que sin saberlo está previsto que acabe en una explotación sexual. El reto del programa ÖDOS es frustrar unos inciertos fines de explotación. 
La ecuación se completa con los NNA que vienen a cargo de esas mujeres. Se trata no solamente de frustrar el fin de explotación, sino de proteger los derechos de esa infancia invisibilizada y en riesgo. Y son precisamente estos NNA los que, a través de estrategias desarrolladas por ÖDOS en coordinación con el Ayuntamiento de Montilla, hacen de ancla para que la mujer se quede el tiempo suficiente para restablecerse, recibir información y establecer lazos con el equipo de intervención que permita un seguimiento futuro. La forma de intervención del programa ÖDOS no priva a la mujer en ningún momento de estar con su NNA, cumpliéndose así las exigencias de una perspectiva de infancia. Tampoco se le priva de otros derechos como pueden ser las comunicaciones a través de sus teléfonos móviles o internet. Es cierto que en otro tipo de programas se pacta con la mujer que quiere salir de la red de explotación sexual el no uso del móvil con la intención de romper lazos con sus captores. Eso solo es viable en una prevención terciaria de la victimización en la que se encuentra, esto es, como estrategia para salir de una red que ya la explota o cuando se reconoce dentro de ella. En el caso del programa ÖDOS, esa negociación no es viable en la medida en que las mujeres aún no han sido explotadas sexualmente ni se percatan del engaño. El programa es una parada forzada en un camino que ellas desean continuar. Al inicio, lo que las retiene es una advertencia verbal por parte de los servicios sociales del Ayuntamiento de Montilla de que no pueden abandonar el recurso hasta que no salgan los resultados de las pruebas de ADN que comprueba la relación de filiación. El programa solo dispone de unas pocas semanas para ganarse la confianza de la mujer, antes de que esta vuelva a emprender el viaje. Esto coloca al programa, desde el punto de vista de la prevención secundaria de la victimización, en una situación difícil porque, aunque los resultados indican que la mayoría permanece en La Muela el tiempo de tres meses establecido, la mayoría rechaza la derivación a segunda fase. De ahí la importancia que debe dar el programa a la formalización del seguimiento posterior de la mujer que abandona el recurso para seguir su trayecto migratorio.

Casi el $90 \%$ de las mujeres continúan su trayectoria migratoria y con mucha probabilidad de camino a su explotación sexual. De ese casi $90 \%$ solo se ha tenido un seguimiento informal durante unos 6 meses de un tercio de las mujeres. Del resto se desconoce su destino. La formalización del seguimiento de las mujeres, a través de contactos sólidos en Francia por ser el lugar de destino de casi todas ellas, permitirá, por una parte, que tras el aprendizaje, acompañamiento y cercanía de ÖDOS, la mujer que se encuentre en una situación de explotación sea capaz de dar la voz de alarma para salir de ese enjambre. Por otra parte, solo a través del seguimiento se podrá conocer el verdadero impacto a medio y largo plazo de este programa de prevención secundaria.

Por otro lado, un aspecto destacado del programa es la alta calidad de la protección jurídica brindada a mujeres y NNA. La perspectiva de infancia ha permitido visibilizar los problemas que afrontan estos menores e iniciar estrategias de protección poco exploradas hasta el momento como los informes de riesgo de los NNA. La perspectiva de género ha conseguido que algunas usuarias puedan solicitar protección internacional, visibilizando que estas mujeres sufren violencia de género, matrimonios forzados, mutilación genital y opresión política, tal y como apunta Torres Falcón (2011). Por ello, 
se considera que el programa también ha conseguido con ello una mejor protección de las usuarias en términos jurídicos.

Los resultados de este programa permiten además abrir un debate sobre la necesidad de que este tipo de intervenciones sea asumido por la Administración pública en sus planes de lucha contra el delito de trata de personas y de protección de una infancia en movilidad. Igualmente, los resultados que se presentan invitan a reflexionar sobre la pertinencia de asumir un enfoque de prevención secundaria de la victimización hasta ahora inexplorado y de atender de manera especial a una infancia vulnerable a pesar de estar acompañada por un adulto.

El programa ÖDOS es una plataforma privilegiada de protección de mujeres africanas y NNA que las acompañan. Los resultados de la evaluación muestran que sus dos objetivos iniciales de prevención secundaria de la explotación sexual y la protección de la infancia acompañada en movilidad mantienen de manera clara su vigencia especialmente en el entorno geográfico andaluz. Al mismo tiempo, hay que valorar positivamente la capacidad de adaptación del programa a los diferentes perfiles de mujeres que llegan a La Muela y aprovechar la oportunidad que supone el recurso residencial de fase I para detectar situaciones susceptibles de ser objeto de protección internacional. En ningún caso este nuevo objetivo es incompatible con la prevención secundaria de la victimización y la protección de la infancia en movilidad. El desafío está en encontrar fórmulas de seguimiento de las familias que deciden seguir su trayecto migratorio tras la parada en ÖDOS. Esa parada en el camino ha demostrado ser importante para el restablecimiento de las familias y para activar estrategias de protección de mujeres y menores, pero estas pueden perderse en el trayecto migratorio hasta su destino final.

\section{BIBLIOGRAFÍA}

AGENCIA DE EVALUACIÓN Y CALIDAD - AEVAL (2015). Guía práctica para el diseño y la realización de evaluaciones de políticas públicas. Enfoque AEVAL. Agencia de evaluación y calidad. Ministerio de Hacienda y Administraciones Públicas.

ARCE JIMÉNEZ, E. (2019). Menores víctimas de trata. Revista Crítica Penal y Poder, $18,278-296$.

BHABHA, J. (2009). Arendt's Children: Do today's Migrant Children have the Right to have Rights? Humans Rights Quaterly, 31, 410-451.

BARUDY, J. (1998). Los buenos tratos a la infancia. Parentalidad, apego y resiliencia. Ed. Gedisa.

CHELIMSKY, E. [ed.] (1985) Program Evaluation: Patterns and Directions. Washington, DC: ASPA PAR Classics VI. 
DEFENSOR DEL PUEBLO (2012). Informe anual DEFENSOR DEL PUEBLO Informe Anual a las Cortes Generales 2012.

ECHEBURÚ, E. y AMOR, P.J. (2019). Memoria traumática: estrategias de afrontamiento adaptativas e inadaptativas. Terapia Psicológica, Vo. 37, $\mathrm{n}^{\mathrm{o}} 1$.

FISCALÍA GENERAL DEL ESTADO (2014) Memoria año fiscal 2014. Ministerio Fiscal.

FISCALÍA GENERAL DEL ESTADO (2019) Memoria año fiscal 2019. Ministerio Fiscal.

FRIESE, S. (2019). Qualitative Data Analysis with ATLAS.ti (3 edition). Sage.

GARCÍA-ESPAÑA, E., CARVALHO DA SILVA, J. CASADO PATRICIO, E, y PRADO MANRIQUE, B. (2020). Resumen ejecutivo: Evaluación Programa ÖDOS.

HELLINGER, B. (2000). Órdenes de amor. Ed. Herder.

JUNTA DE ANDALUCÍA (2016). La Evaluación de Políticas Públicas. Instituto Andaluz de administración pública - Conserjería de hacienda y administración pública.

Recuperado

de: http://www.juntadeandalucia.es/institutodeadministracionpublica/institutodeadm inistracionpublica/publico/anexos/evaluacion/EvaluacionPoliticasPublicas.pdf

MANZANEDO NOGUERUELA, C. (2019). Menores extranjeros acompañados. La problemática invisible de los niños y niñas migrantes acompañados que llegan a la frontera sur española. Revista Crítica Penal y Poder, 18. 260-266.

MONTIEL TORRES, O. (2009). Trata de personas: padrotes, iniciación y modus operandi. México: Instituto Nacional de las Mujeres.

ROSSI, P.H. \& FREEMAN H.E. (1989). Evaluación. Un enfoque sistemático para programas sociales. Traducción de la 2 ed. en inglés. Trillas.

SALAT PAISAL, M. (2020). Análisis descriptivo de sentencias sobre trata de personas: Un estudio de casos judiciales entre 2011 y 2019. Revista Española De Investigación Criminológica, 18(1), 1-27. https://doi.org/10.46381/reic.v18i1.405

SÁNCHEZ TOMÁS, J. (2020). Mesa: La mujer migrante. VIII Cumbre de mujeres juristas. Ilustre colegio de abogados de Madrid. 29 y 30 de octubre. Recuperado de:

https://www.youtube.com/watch? feature=youtu.be\&v=R2HVBOeZne4\&app=de sktop 
STUFFEBEAM, D. \& SHINKFIELD, A. (1987). Evaluación sistemática: guía, teoría y práctica. Barcelona. Paidos. taking [Versión electrónica]. Journal of Educational Psychology, 95(2), 335-346.

THILL, M. y GIMÉNEZ ARMENTIA, P. (2016). El enfoque de género: Un requisito necesario para el abordaje de la trata de seres humanos con fines de explotación sexual. Revista Europea de Derechos Fundamentales, 27, 439-459.

TORRES FALCÓN, M. (2011). Explotación sexual y violencia de género: un debate de derechos humanos. Nova et Vetera 20(64), 151-164.

TRIBUNAL EUROPEO DE DERECHOS HUMANOS (TEDH) (2013) caso R.M.N c. España, N. ${ }^{\circ} 28775 / 12$ (18 de junio de 2013).

VAISMORANDI, M., TURUNEN, H., \& BONDAS, T. (2013). Content analysis and thematic analysis: Implications for conducting a qualitative descriptive study. Nursing \& Health Sciences, 15, 398-405. https://doi.org/10.1111/nhs.12048

VILLACAMPA ESTIARTE, C. (2011). El delito de Trata de Seres Humanos: una incriminación dictada desde el derecho internacional. Aranzadi-Thomson Reuters.

VILLACAMPA ESTIARTE, C. y TORRES FERRER, C. (2021). Aproximación institucional a la trata de seres humanos en España: Valoración crítica. Estudios penales y Criminológicos. Vol. XLI.

WEISS, C. H. (1998). Evaluation. Methods for Studying Programs and Policies. Second Edition. Prentice Hall 